\title{
Group psychotherapy with spinal cord injured substance abusers
}

\author{
M Perez MSW, ${ }^{1}$ C Pilsecker MSSW ${ }^{2}$ \\ ${ }^{1}$ Social Worker, Special Treatment Unit, ${ }^{2}$ Supervising Social Worker, Spinal Cord Injury \\ Service, VA Medical Center, 5901 E. 7th Street, Long Beach, CA 90822, USA.
}

\begin{abstract}
Some studies have suggested that nondisabled people follow the dictates of a 'kindness norm' when reacting to those who are disabled. Spinal cord injured substance abusers have sometimes used the kindness of others to help maintain their addictive behavior. A special unit for such substance abusers in a Veterans Affairs hospital has used group psychotherapy as one of the principal methods for moving beyond the kindness norm and challenging its patients to struggle with their substance abuse. Therapists in this group have had to become aware of the special content of denial in this population, of the role of physical problems specific to spinal cord injury, and of the need to set aside clinical issues at times in order to make on the spot reponses to practical problems associated with the injury.
\end{abstract}

Keywords: group psychotherapy; spinal cord injury; substance abuse.

\section{Introduction}

When a spinal cord injured person needs treatment for substance abuse, a basic question is whether or not the treatment program should be exclusively for the spinal cord injured. In a standard community program the spinal cord injured individual will likely be the one person in a wheelchair and his/her peers will be unfamiliar with some of the basic facts of living with the injury. Does this help or hinder the abuser's progress toward recovery? Or is it irrelevant?

Some researchers suggest that there is a 'kindness norm': 'an apparent tendency to treat and respond to persons with visible disability with overt lenient criteria and covert behavior avoidance'. ${ }^{1}$ If this is true, the spinal cord injured person whose therapy is exclusively in a heterogeneous support group or treatment center may not receive full benefit from the program. Leniency from one's nondisabled substance abusing peers may well contribute to a maintenance of the denial which is one of the major obstacles to a substance abuser's recovery.

Nineteen years ago the Spinal Cord Injury
Service of the Long Beach VA Medical Center decided to set up a special treatment unit for spinal cord injured substance abusers which would include both spinalcord-injury-exclusive activities and nonexclusive ones. The comprehensive program serves 10 inpatients at a given time plus an indeterminate number of outpatients who have been through the inpatient program. ${ }^{2}$ The principal author has been the unit's social worker for 10 years.

The hundreds of spinal cord injured veterans who have wrestled with their addiction in and through this unit have been little different from other substance abusers in some respects. Many of them have denied the degree of their substance use and its negative effect on their lives in spite of the outcries of family and friends. Many of them have sworn off 'forever' and reverted, over and over, to using their drug of choice. Many of them have encouraged significant others to covertly aid and abet the continuance of their habit. Almost all of them have been abusers and selected these behaviors prior to their injury. For some, being under the influence was a fundamental factor in their becoming injured. So they have 
adapted a wheelchair and their physical limitations, as best they could, to their familiar lifestyle.

Yet there can be important differences. The paraplegic person, if he has transportation, may be able to obtain his alcohol or drugs as easily as before. The individual who is quadriplegic, however, may need assistance not only for securing but also for the administration of his chosen substance. Both, like their able bodied comrades in addiction, will seek out family members and friends to be co-dependents, but there is a new dynamic: sympathy. It does not replace the now widely recognized co-dependency motivations. ${ }^{3.4}$ It supplements them. 'Look at the life the poor guy leads. Why deprive him of his pleasure?' 'If I were in his wheelchair, I would probably hit the bottle, too.' Examples abound among the special unit's patient population: the sister who tried to cheer up her bedridden, depressed paraplegic brother by purchasing alcohol regularly for him; the well meaning grandmother of a 35 year old paraplegic veteran who paid his rent and gave him money for drugs; the nonusing mother of a quadriplegic young man who rolled his marijuana joints for him. Hospital rehabilitation staff of all disciplines sometimes get caught up in feeling sorry for the spinal cord injured patient whom they are treating and minimize or excuse or even contribute to the injured person's substance abuse.

Extrapolating from the special unit's population suggests that a kindness norm does exist and, to some degree, persists even in long term relationships. A wheelchair, as a permanent fixture of a person's life, is apparently sufficiently visible and impactful that it can influence the behavior of others in a continuing manner.

That does not mean, however, that a spinal cord injured individual's social network will indefinitely tolerate difficult behavior. Eventually, when the emotional battering becomes too great, even sympathy-induced coddling may give way and the family member or friend may stop cooperating or may leave-for a while. The usual addiction scenario will likely materialize: a sad, sober and contrite ex-user will sooner or later resurface and the sympathetic other, faced with the appealing human being plus his wheelchair, will re-engage - for a while.

\section{Content of denial}

Characteristically substance abusers will deny that their substance use constitutes a problem by espousing one or both of two propositions: (1) I don't use much; (2) using doesn't adversely affect my life.

For the spinal cord injured addict, these verbal maneuvers are also available and used, but another tends to rise to sometimes equal prominence. It is the other side of the coin to the co-dependent's sympathy dynamic: 'I've got good reason to drink/use.' The sudden, irreversible consequences of the traumatic injuring event suffuse all aspects of the individual's life: personal, interpersonal, occupational, avocational. The person who, before injury, has been used to having drugs and alcohol to smooth out life's rough edges now encounters new and greater rough edges which serve as new rationales for old habits. Functional limitation and dependence on others add fuel to the substance abuser's fire.

In addition to these core experiences of spinal cord injured persons, there are the concomitants of the injury which can cause distress: the awkwardness of other people's responses to them; the involuntaries; the spasms ... A person who had to use drugs to make life tolerable before injury may find these periodic insults especially onerous and may now feel that he has substantial justification for resorting to his habitual comfort producers. The substance use is not a problem; it is an entitlement.

Unpleasant injury-related events can actually have a dual effect on the substance abuser. Not only will an embarrassing moment give immediate momentum to a decision to use one's favorite substance, but the distasteful memory of it may propel him into social isolation. Special unit patients have reported that even another spinal cord injured person's story of an unhappy incident has led the hearer to try to avoid encountering a similar misfortune by minimizing interaction with others. What do drinkers and users do to make a dreary life 
less dreary? Drink and use. The noose becomes tighter.

\section{The special unit's program}

For very individualized reasons, at some point, for some abusers, the denial begins to soften, the entitlement begins to lose its appeal, the social isolation begins to be too painful. The person turns-or again turns - to the special treatment unit for help. Programmatically the unit features family therapy, community meetings, outings, required attendance at Alcoholics Anonymous (AA) meetings (usually within the medical center), and, as its cornerstone, group psychotherapy. The group meets four times a week and is led by two therapists. The therapist role is shared by the ward social worker, the readjustment therapist, and the psychiatrist who directs the program. By requiring AA attendance, the unit both acknowledges the efficacy of the AA approach and encourages the spinal cord injured individual to engage himself with the nondisabled community. By offering its own group psychotherapy, the program takes account of the fact that the unique issues of living with a spinal cord injury are usually unrecognized and unattended to in nonSCI groups. Also, it moves the patients past the 'kid glove' treatment that they often report having received in community programs because of their very visible disability.

The psychotherapy group uses essentially the same principles and techniques as other issue-focused psychotherapy groups. ${ }^{5}$ The application of these principles and techniques is shaped by the reality of the group members' injury. Difficult experiences are generalized: 'Yeah, I've had people stare at me. We all have.' The special hurts, embarrassments, and frustrations attendant to being spinal cord injured are acknowledged. Encouragement and support are provided. This happening and that happening are tied together in the process that is called insight. Some tricks of the trade for dealing with the facts of spinal cord injury are offered, usually by group members. An individual is confronted with his contribution to an unhappy experience. Assertiveness is both taught and rewarded so that the injured person can comfortably ask for the help he needs. Group members are challenged to find means other than substance abuse for coping with paraplegia or quadriplegia. The participants know that, in this group, the others are not just being kind to a poor cripple when they talk about being able to live through the unique challenges of their disability. They also quickly learn that there is no kindness norm here. Their injury and its accoutrements will not excuse them from striving to become substance free.

\section{Addressing physical problems}

Two physical problems continuously loom as threats to a spinal cord injured person's health: urinary tract infection (UTI) and pressure sores.

When an individual is experiencing the chills, fever, loss of appetite and overall debility produced by a UTI, he is unlikely to vigorously engage in any activity, including group psychotherapy. When the infection wanes, though, the illness, instead of soliciting the sympathy one expects and customarily receives when ill, may instead call forth scrutiny from the group. Why did it happen? Was it just a fact of spinal cord injury life that can inject itself unpleasantly into anyone's routine or was it somehow related to substance abuse behavior? Was the paraplegic victim of a UTI soberly and scrupulously adhering to the clean technique for performing his catheter changes or was he too loaded to do them carefully and on schedule? Did the quadriplegic person cooperate with his attendant in catheter care or was he drunk and obstreperous, resisting the attendant's efforts to empty his leg bag before an overload caused urine to back up in the bladder?

Pressure sores, too, can present grist for the psychotherapeutic mill. Although almost any spinal cord injured person, no matter how careful, can sustain a pressure sore which may keep him in bed for weeks at a time, there are certain people, with substance abusers foremost among them, who seem almost to court this kind of disaster. A person gets inebriated, falls out of his wheelchair, scrapes his buttock, setting the stage for development of a sore. 
Under the influence, the spinal cord injured individual 'forgets' to lift himself from his wheelchair to relieve pressure on his ischial tuberosities or his sacrum; neglects turning himself or summoning assistance to turn in bed to relieve pressure on his trochanter; or he does not notice that his heels and/or ankles are pressed hard and long against the leg rests of his wheelchair. Sitting too long can precipitate skin breakdown; one can easily lose track of time when running around town trying to make a drug connection. Transferring from wheelchair to bed, the loaded abuser may accidentally pull his urinary condom off, spilling urine on himself; too distracted to deal with the matter, he leaves the urine to soak and eventually break down his skin. One special unit patient admitted to hiding hot crack pipes in his socks. With no sensation of pain, he was oblivious to the destruction of the skin on his leg that was occurring.

The nondisabled world may respond sympathetically to the plight of the individual who, on top of his spinal cord injury, develops a debilitating sore on leg or buttocks. Seeing a young man in a wheelchair is sad enough; to see him confined to a gurney (a wheeled stretcher or cart for the transport of patients usually within a hospital) is sadder still. But the special unit psychotherapy group is likely to be less kind hearted and will want to pursue the connection between behavior and ugly outcome.

\section{Challenges to therapist}

It is essential that the therapist become fully informed about the special struggles of the spinal cord injured person. This does not mean that the therapist must be spinal cord injured. If $s /$ he is, $s /$ he has a head start as long as $\mathrm{s} / \mathrm{he}$ does not insist that her/his post injury course is the spinal cord injury experience. Drawing on one's own life and/or from careful attention to the lives of others, the therapist will look for opportunities to elicit from group members the comment or challenge or confrontation that may result in a therapeutic exchange. For example, if the therapist, whether spinal cord injured or not (none of the special unit's therapists are), knows that autonomic dysreflexia can result when a quadriplegic or high-level paraplegic develops a kink in his catheter, then the therapist can make sure the group responds probingly to a member's report of having had, or almost had, dysreflexia. How did it come about? What was the individual's contribution to his distress? Was substance abuse a factor in what happened?

No therapist ever reaches the pinnacle of awareness, so leading a psychotherapy group - any psychotherapy group - is sometimes a humbling experience. Patients make new, sometimes startling revelations. The safest stance for any therapist, old or new, similarly disabled or not, is to acknowledge to oneself: 'I know a lot; there is more to learn'.

In the special unit psychotherapy group, clinical judgment must be directed, at times, to 'at-this-very-moment' happenings that are specific to spinal cord injury. A patient leaves the therapy group early, ostensibly to empty the urine from his leg bag. In itself, that is an essential, health preserving procedure. But is the leg bag really full? Or is the topic of discussion so painful that the patient has to escape and uses the leg bag maneuver to try to make it acceptable? If the leg bag is full, are there questions that need to be raised about why the patient did not plan ahead so he could make it through the psychotherapy session without interruption?

Then there are the events that require both clinical judgement and practical action. A member of the group has the prototypical spinal cord injury embarrassment: an involuntary bowel movement. He may ask to leave to clean up. The request will be instantly granted. Upon his return he may be offered recognition of the difficulty of the experience, encouraged to speak of his feelings about it, involved in a discussion of how to deal with such an accident in the community. Or, if the patient has a history of sometimes refusing bowel care when he is due for it, thus contributing to his 'accident', the group may have to try to help him wrestle with this. The person who had the accident may initially decide, however, to remain in the group and clean up later. Then clinical issues may momentarily need to step aside while a towel or two is put in 
place and a window opened. Spasms may take a patient's attention away from the group for a time; the group will go on. When a leg bag leaks, paper towels may be called for along with clinical astuteness.

\section{Use of context}

Most of the members of the special unit's psychotherapy group at a given moment are inpatients. This means that a body of information is available to the therapists concerning the patients' behavior on the ward. The treatment team meets daily with the therapists to share what has been happening. If patient Smith has cursed the nurses while they were getting him ready for bed the night before this may well become a topic for the group. If patient Brown, formerly surly and minimally compliant, has become more pleasant and cooperative, this will be offered to the group for its applause.

\section{The kindness norm}

A kindness norm appears to contribute to the development of co-dependence among significant others of spinal cord injured substance abusers and to make it more difficult for abusers to receive therapeutic assistance in the nondisabled community. It is consciously set aside by the therapists in the special unit psychotherapy group. Perhaps this means they are cruel. Some patients have so alleged, although some of these patients' allegations have been withdrawn after the patient has been sober/nonaddicted for a time.

Cruelty is what hurts the other for no reason of benefit to him. We do not consider surgeons to be cruel in spite of the pain they inflict. All therapists working with substance abusers have seen the hurt that kindness, as commonly described, can produce as the addiction is shored up instead of attacked. So, in eschewing this brand of kindness, the special unit therapists follow usual therapeutic technique. But they have to go one step farther and acknowledge to themselves and their patients that just as a wheelchair does not define the person in it, neither should a wheelchair deflect the sometimes surgically sharp strokes necessary to try to move a person toward sobriety.

\section{Conclusions}

Group psychotherapy is a basic element of most substance abuse treatment programs, recognizing both the importance of support from one's peers in struggling to overcome addiction and the special penetrative power of challenges from those who know, first hand, what substance abuse is all about. The special treatment program for SCI substance abusers has demonstrated the usefulness of an exclusively SCI therapy group as one part of a comprehensive therapeutic package.

\section{References}

1 Elliott T, Frank R (1990) Social and interpersonal reactions to depression and disability. Rehabil Psychology 31 135-145.

2 Reinbold W (1991) Management of coping problems in spinal cord injury rehabilitation. In Lee B, Ostrander L, Cochran G, Shaw W, editors. The Spinal Cord Injured Patient: Comprehensive Management. W B Saunders Company, Philadelphia: 283-290.

3 Beattie M (1987) Co-Dependent No More. Harper \& Row, New York.

4 Weinhold J (1986) Breaking Free of the Co-Dependency Trap. Stillpoint Publishing, Walpole, New Hampshire.

5 Yalom I D (1985) The Theory and Practice of Group Psychotherapy. 3rd ed. Basic Books, New York. 